\title{
Effects of chronic low frequency electrical stimulation on normal human tibialis anterior muscle
}

\author{
OM SCOTT, G VRBOVÁ, ${ }^{*}$ SA HYDE, V DUBOWITZ† \\ From the Departments of Physiotherapy and Paediatrics, $\dagger$ Hammersmith Hospital and Department of \\ Anatomy and Embryology, ${ }^{*}$ Centre for Neuroscience, University College, London, UK
}

SUMMARY The loss of force that occurred during intermittent electrically evoked tetanic contractions was determined for the tibialis anterior muscle of normal subjects. Adult muscles showed a characteristic reduction of tension over the first two to three minutes until a steady plateau was reached. Muscles of young children showed no comparable decrease of the initial tension in response to this method of fatigue testing. After fatigue the muscles of both groups of subjects produced a higher proportion of tension at lower rates of stimulation. Following prolonged chronic low frequency stimulation at $8-10 \mathrm{~Hz}$, adult muscles showed a significant increase $(\mathrm{p}<$ 0.01 ) in fatigue resistance compared to unstimulated control: the muscles of the normal child showed no measured change. It is concluded that it is possible to alter the properties of adult human muscle by superimposed low frequency electrical stimulation.

Investigations on animals have shown that it is possible to modify the properties of mammalian skeletal muscles by chronic electrical stimulation. Fast twitch muscles of cats and rabbits have been induced by chronic low frequency stimulation to exhibit properties of slow contracting twitch muscles. An early effect of such stimulation is an increase in resistance to fatigue with an increase in capillary density and oxidative enzymes. These changes occur before an observable change in contractile properties.' The purpose of this study was to establish whether similar increases in resistance to fatigue could be induced in human skeletal muscle.

In previous experiments, measurements of resistance to fatigue of human muscles have been based upon the decrease in tension, or changes in electrical activity using electromyography, either during voluntary contraction, or prolonged electrical stimulation. ${ }^{2-5}$ In assessing resistance to fatigue during voluntary contraction, account must be taken of the motivation of the subject and other influences that are difficult to control. In contrast, tests using pro-

Address for reprint requests: Dr OM Scott, Physiotherapy Department, Hammersmith Hospital, Du Cane Road, London WI2OHS, UK.

Received 30 March 1984 and in final revised form 5 December 1984.

Accepted 15 December 1984 longed electrical stimulation are easier to interpret. In this case, fatigue is probably caused by the $\frac{\rho}{\mathbb{Q}}$ 을 decrease in tension of high threshold motor units, $\stackrel{\varnothing}{\triangle}$ which normally are not used during sustained voluntary contraction (for review see ref 6 ).

Most data on human muscles are obtained from adult subjects, and little is known of how human skeletal muscles change during development in childhood. In this study, an attempt was made to compare some physiological characteristics of adult muscle with that of young children. On the basis of work with animals, it can be expected that chronic electrical stimulation will increase the resistance to fatigue of mature muscle. We were concerned to investigate any changes in resistance to fatigue following a prolonged period of chronic low frequency stimulation as shown by changes of response to an electrically stimulated test of muscle fatigue.?

\section{Method}

\section{Subjects}

Sixteen normal adults (six males and 10 females), varying in age from 17 to 53 years, and 18 normal children ( 15 boys and three girls) of age range 3 to 13 years took part in the study. All the subjects were normal, healthy volunteers and the studies were approved by the Committee on Ethics of Clinical Investigations of Hammersmith Hospital.

Measurements were made of maximum voluntary and electrically evoked contractions of the tibialis anterior muscles in all subjects. In order to evaluate the effects of 
chronic low frequency stimulation, five female adults and one 11 -year-old girl stimulated their tibialis anterior muscles at a frequency of $10 \mathrm{~Hz}$ or less for an hour. three times daily for $h$ weeks.

\section{Assessment procedure}

To ensure standardisation of position and fixation of the limb during assessment, a special chair was designed (fig 1). The position of the seat and leg supports were adjusted to the individual and then firmly secured. Two sets of footplates were provided. one was made of stainless steel and of dimensions suitable for adults, the other set made of aluminium, was built on the same design principle and was used for measuring in children. Strain gauges mounted on the upper surface of a mild steel bar measured the tension exerted by the tibialis anterior muscles. The bar was mounted at $20^{\circ}$ to horizontal on two supporting pillars and its height could be readily adjusted by two self-locating screws. Moulded padding on the under surface of the bar ensured optimum force transmission from the contracting muscle group. Two bars were provided, one of $3 \mathrm{~mm}$ thickness which gave a measuring range suitable for adult subjects and one of $1 \mathrm{~mm}$ thickness which was more sensitive and was suitable for measuring the forces exerted by the children. The subjects were secured to the seat by an adjustable seat belt, sat upright with their thighs supported, their knees flexed to 90$)^{\circ}$ and their feet resting on two rigid footplates as shown in fig 1 . Two correctly sized heel cups were fitted and the padded bar against which the

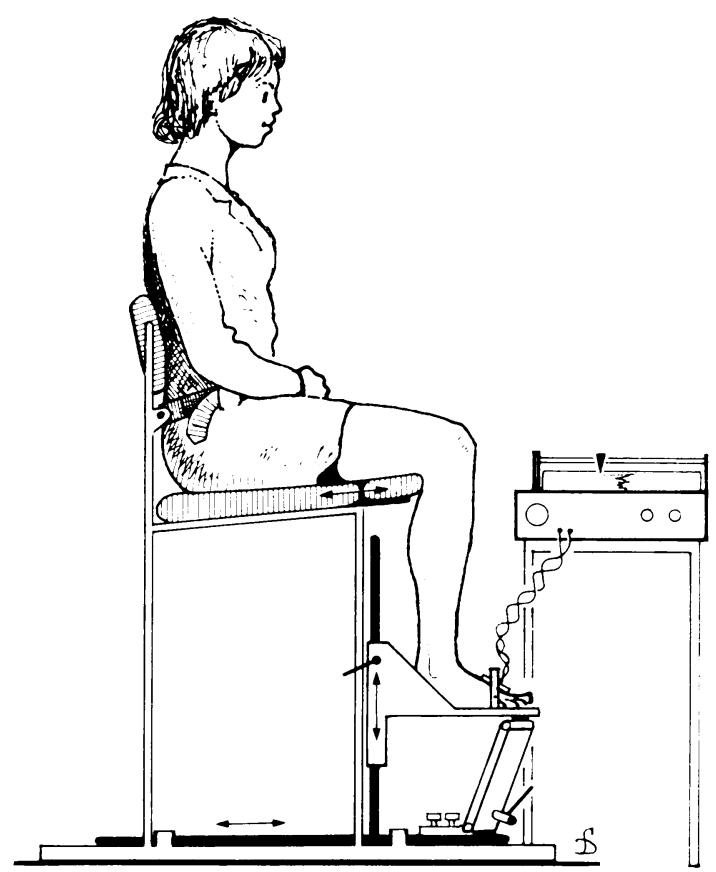

Fig 1 Apparatus for measuring strength of tibialis anterior muscle. subject pulled was adjusted so that it was comfortable. Particular care was taken to ensure that the foot was positioned so that the bar was aligned with the head of the first metatarsal bone. The subject was asked to make maximal effort to dorsiflex against the bar and the output from the strain gauges was fed through amplifiers on to a pen recorder. The best of three attempts was taken as the maximum voluntary contraction, unless the third was greatest in which case a fourth attempt was made and if greater, repeated until a maximum was established. A standard constant voltage stimulator (Digitimer Type 3072) connected to two $4 \mathrm{~cm}$ square carbon rubber electrodes placed over the motor point and on the belly of the muscle was used in stimulation. Good contact was ensured by using electrode jelly and the electrodes were secured by adhesive tapes. Isometric contractions of the tibialis anterior muscle were thus elicited by stimulating the intramuscular branches of the lateral popliteal nerve using a square wave pulse of $50 \mu$ s duration. applied at selected frequencies for $250 \mathrm{~ms}$ each second. A routine sequence of testing was established to record the increments of tension in response to brief trains of stimulation at $1,10,20$ and $40 \mathrm{~Hz}$. To determine resistance to fatigue, the muscle was stimulated at $40 \mathrm{~Hz}$ for $250 \mathrm{~ms}$, every second for 5 minutes and the percentage decrease of tension after three minutes was measured.

The effect of this fatigue test on the tension elicited by brief trains of stimulation was established (fig 2), by
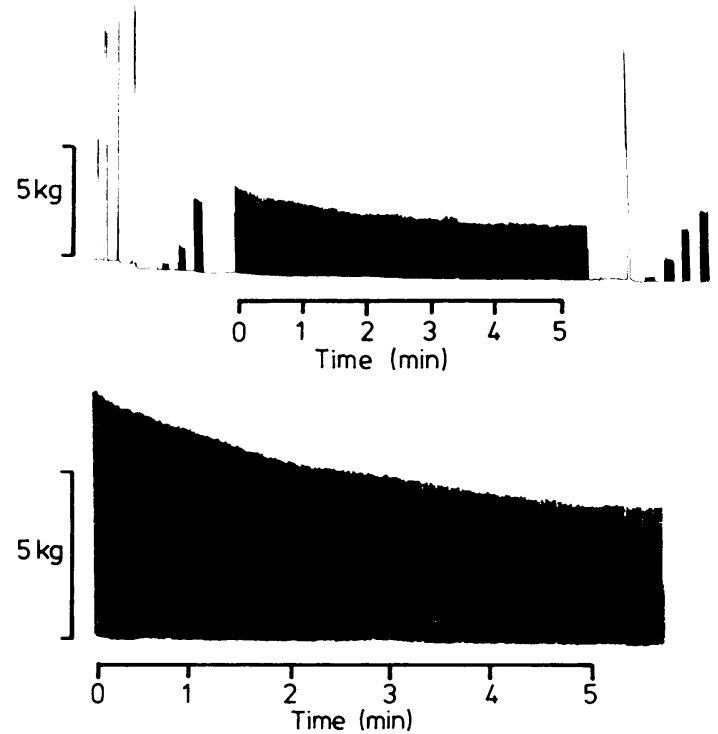

Fig 2 Records of routine sequence of testing of the tibialis anterior muscles of two normal adult subjects, (a) shows the response to testing of subject (AT), her maximum voluntary contraction and the increments of tension in response to brief trains of stimulation at $1,10,20$ and $40 \mathrm{~Hz}$ before and after fatigue. (b) shows the typical response to fatigue testing, subject $(M D) F I=23 \%$. 
recording the tension developed at $1,10,20$ and $40 \mathrm{~Hz}$ before and after fatigue. The following ratios were determined:

$$
\frac{\text { Tension }(10 \mathrm{~Hz}) \times 100}{\text { Tension }(40 \mathrm{~Hz})} \text { and } \frac{\text { Tension }(20 \mathrm{~Hz}) \times 100}{\text { Tension }(40 \mathrm{~Hz})}
$$

A Fatigue Index (FI) at $40 \mathrm{~Hz}$ was then calculated as follows:

$$
\text { FI }=\frac{\begin{array}{c}
\text { Initial Tetanic Tension-Tetanic Tension after } \\
3 \text { minute stimulation }
\end{array}}{\text { Initial Tetanic Tension }}
$$

A prelimary study of six normal adults and six normal school children aged 5 to 12 years indicated that this method of assessment was well tolerated and between 20 and $50 \%$ of the maximum voluntary force could be elicited on stimulation at $40 \mathrm{~Hz}$.

Chronic low frequency stimulation

The subjects stimulated their tibialis anterior muscles with a small battery operated stimulator at frequency of $5-10 \mathrm{~Hz}$ for an hour, three times daily for six weeks.

Stimulation was by two $4 \mathrm{~cm}$ square carbon rubber electrodes placed medial to the head of the fibula over the motor point and more distally on the belly of the muscle; these were attached by leads to the stimulator which was worn on the belt around the waist. The subjects were instructed to adjust the position of the two electrodes on the muscle and the output of the stimulator to give sufficient stimulation to see a visible contraction of the tibialis anterior muscle accompanied by movement of the foot. The tension developed by this stimulation was found to be the same as that recorded on assessment when the muscle was stimulated at $10 \mathrm{~Hz}$, that is about $25 \%$ of the tension developed by the muscles at $40 \mathrm{~Hz}$. A day by day chart of hours of stimulation was made and kept by each subject.

Initial base line data on the contractile properties of the tibialis anterior muscle for each subject were established by the investigator prior to commencing long-term stimulation. Further testing was undertaken after three weeks and six weeks of stimulation and at six months after completion of stimulation.

\section{Data handling}

Scatter graphs and regression lines were drawn and linear regressions were plotted for analysis of the data. Results in the text and tables have been expressed as means with standard deviations throughout the text. The significance levels of difference between mean values have been calculated using paired and unpaired Student's $t$ tests.

\section{Results}

Validation of method of assessment

A series of six normal adults were assessed in the manner described and then reassessed a week later. The results are shown in table 1 and show that the assessment procedure gave results that were highly reproducible.

The interval between the two tests of the six normal school children varied from one week to a maximum of three months and these results are shown in table 2. These indicate more variability than in the adult study; this can be accounted for partly by the longer interval between the two tests, and the inherent variability of young children.

It has been suggested that percutaneous stimulation of part of a muscle may be unsatisfactory and that the relationship between high and low frequency force generation is voltage dependent. ${ }^{\mathrm{R}}$ Further investigations have shown that the relationship is robust except at the lowest voltages when forces of less than $10 \%$ of maximum voluntary contraction are generated."

\section{Fatigue testing in adults}

The response to fatigue testing was measured in sixteen normal adults. A typical record is shown in fig 2 , and table 3 summarises the results obtained in all sixteen subjects tested. It shows that on average, about $25 \%$ of the maximum voluntary strength of the dorsiflexors was activated by electrical stimulation.

All subjects showed a decrease of force during the fatigue test. Figure 2 illustrates a typical response of a normal adult subject to fatigue testing, showing ao characteristic reduction of tension over the first two or three minutes, until a steady plateau is main tained. In different subjects, the decrease after thre minutes varied from $15 \%$ to $48 \%$ of the initial force output.

Table 3 shows that following the fatigue test, afte an interval of 2-3 minutes, there was a mean decrease of tension of $0.6 \mathrm{~kg} \pm 0.64$ and $0.4 \mathrm{~kg}$. 0.66 for the right and left leg respectively on restimulation at $40 \mathrm{~Hz}$. Table 3 also shows the proportion of tension developed at $10 \mathrm{~Hz}$ and $20 \mathrm{~Hz}$ both before and after the fatigue test expressed as a percentage of the tension at $40 \mathrm{~Hz}$. In adults, stimulation at $40 \mathrm{~Hz}$ elicited between $85 \%-95 \%$ of maximal tetanic tension. The mean increase developed on stimulation at $10 \mathrm{~Hz}$ following fatigue was $7.8 \%$ $\pm 10.75(\mathrm{p}<0.05, \mathrm{n}=15)$ and $9.95 \% \pm 5.33(\mathrm{p}<$ $0.001, n=9)$ for the right and left legs respectively There was no overall increase in the proportion of tension generated at $20 \mathrm{~Hz}$. These measurements were always recorded within 5 minutes of completion of the fatigue test.

\section{Effect of chronic low frequency stimulation}

The five female subjects stimulated their tibialis anterior muscles three times daily for six weeks. No윽 ill effects were reported and the subjects were all $\$$ able to continue with their normal daily activities? whilst wearing the stimulators.

Figure 3 shows records obtained from one of the 
Table 1 Analysis of test/retest for assessment of six normal adults

\begin{tabular}{lllllc}
\hline & $\begin{array}{l}\text { Coef variation for } \\
\text { duplicates (\%) }\end{array}$ & $\begin{array}{l}\text { Corr coef } \\
(r)\end{array}$ & $\begin{array}{l}\text { Paired } t \\
\text { analysis }\end{array}$ & $n$ & Range \\
\hline $\begin{array}{l}\text { Maximum voluntary } \\
\text { contraction (.MVC) }\end{array}$ & 11.9 & 0.9 & -1.83 & 11 & $9.4-22.6 \mathrm{~kg}$ \\
$\begin{array}{l}\text { Fatigue index (FI) } \\
\text { Before fatigue }\end{array}$ & 6.85 & 0.88 & -0.15 & 11 & $15-62 \%$ \\
$\begin{array}{l}10 / 40 \mathrm{~Hz} \\
20 / 40 \mathrm{~Hz}\end{array}$ & 14.6 & 0.93 & -1.28 & 11 & $7-36 \%$ \\
$\begin{array}{l}\text { Afier fatigue } \\
\quad 10 / 40 \mathrm{~Hz}\end{array}$ & 10.95 & 0.81 & -1.25 & 11 & $43-81 \%$ \\
$20 / 40 \mathrm{~Hz}$ & 19.5 & 0.74 & 0.06 & 11 & $13-35 \%$ \\
\hline
\end{tabular}

Table 2 Analysis of test/retest assessment of six normal children

\begin{tabular}{|c|c|c|c|c|c|}
\hline & $\begin{array}{l}\text { Coef variation for } \\
\text { duplicates }(\%)\end{array}$ & $\begin{array}{l}\text { Corr coef } \\
\text { (r) }\end{array}$ & $\begin{array}{l}\text { Paired } 1 \\
\text { analysis }\end{array}$ & $n$ & Range \\
\hline \multicolumn{6}{|l|}{ Maximum voluntary } \\
\hline Fatigue index (FI) & $11 \cdot 1$ & $(0) 2$ & 1.38 & i0 & $-41-16 \%$ \\
\hline \multicolumn{6}{|l|}{ Before fatigue } \\
\hline $10 / 40 \mathrm{~Hz}$ & $19 \cdot 2$ & 0.47 & -0.87 & 10 & $10-33 \%$ \\
\hline $20 / 40 \mathrm{~Hz}$ & $15 \cdot 2$ & 0.42 & -0.53 & 10 & $39-77 \%$ \\
\hline \multicolumn{6}{|l|}{ Afier fatigue } \\
\hline $10 / 40 \mathrm{~Hz}$ & $21 \cdot 5$ & 0.81 & $2 \cdot 26$ & 10 & $11-46 \cdot 5 \%$ \\
\hline $20 / 40 \mathrm{~Hz}$ & $7 \cdot 6$ & 0.64 & $1 \cdot 58$ & 10 & $47-79 \%$ \\
\hline
\end{tabular}

Table 3 . Mean values $\pm S D$ of maximum voluntary contraction, fatigue indices and the ratios $10 / 40 \mathrm{~Hz}$ and $20 / 40 \mathrm{~Hz}$ before and after fatigue testing in 16 normal adults

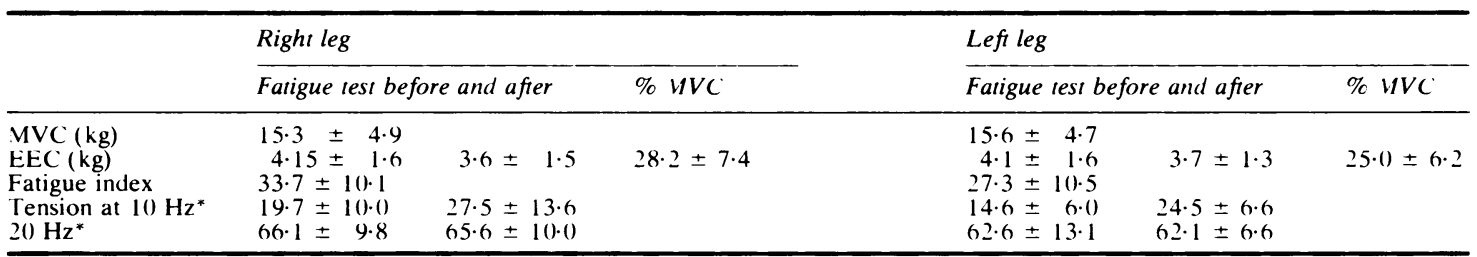

MVC - Maximum voluntary contraction at $40 \mathrm{~Hz}$

EEC - Electrically elicited contraction at $40 \mathrm{~Hz}$

$\pm \quad-\mathrm{SD} \mathrm{N}=15$ for right leg and $n=9$ for left leg

- tension expressed as \% of tension developed at $40 \mathrm{~Hz}$

five subjects (LB). It is clear from these records that the stimulated tibialis anterior muscle had become more fatigue resistant while the unstimulated muscle had not changed during this period. There was no significant change in maximum voluntary contraction in the same period. Table 4 summarises the results obtained from subjects who were stimulating their tibialis anterior muscle for a minimum of six weeks. Before the period of chronic stimulation, all subjects showed a characteristic decrease of force during the fatigue test and at this stage there was no significant difference between the two legs. After six weeks of chronic stimulation, there was a marked change in the fatigueability and in each individual the stimulated muscles fatigued less than the unstimulated control. Their tension decrease was $12 \cdot 3 \pm 5 \cdot 8 \%$, less than before stimulation started. While the overall change of the fatigue index of the control muscles during the same period was only $0 \cdot 18 \pm 3.5 \%$. The difference between the fatigueability of the control and stimulated muscle was highly significant $(p<0.01)$. Thus stimulation reduced fatigueability of the muscles.

As in the previous group of normal adults, the percentage of tension developed at $10 \mathrm{~Hz}$ and $20 \mathrm{~Hz}$ before and after the fatigue test was assessed. There was no consistent difference between the tensions developed by the control and chronically stimulated tibialis anterior muscles. This indicates that while the chronic stimulation increased the fatigue resistance of the muscle, it did not have an appreciable effect on the contractile properties.

Change of the muscle properties during development The muscle strength of normal children increased with age. Figure 4 shows that there is a linear rela- 
Control leg
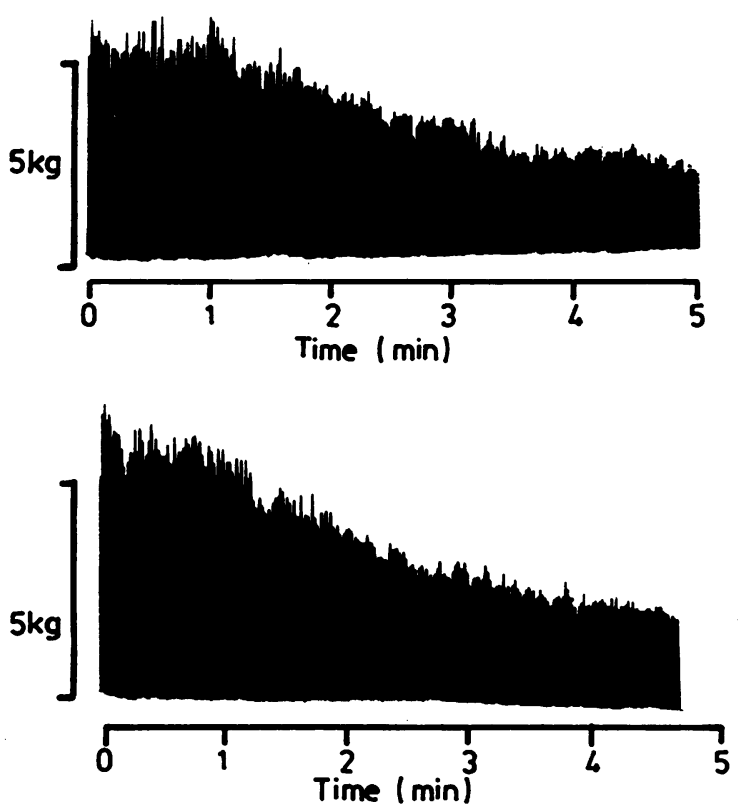

Stimulated leg
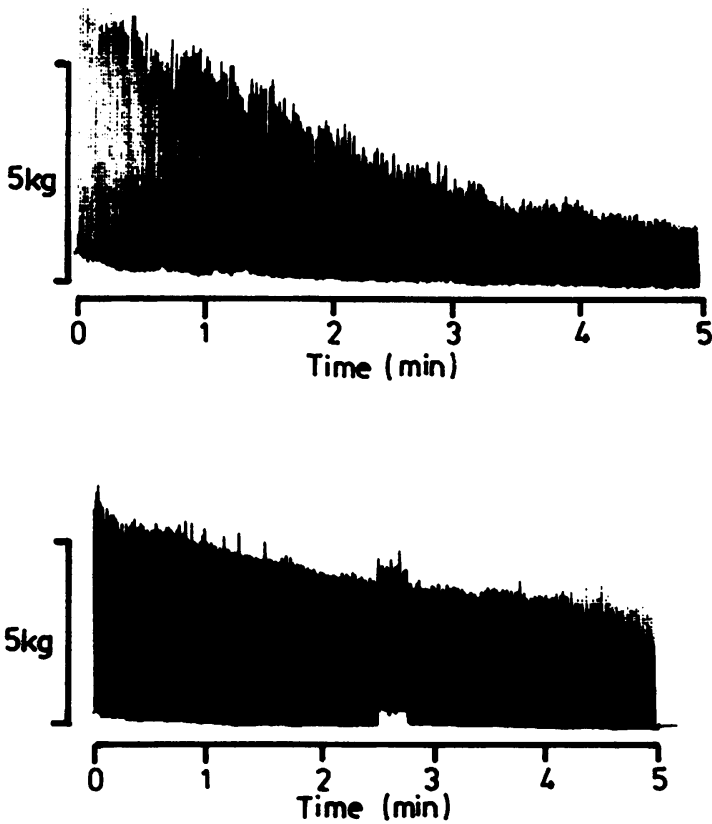

Fig 3 Records of fatigue tests of one of the five normal adult subjects $(L B)$ of the control and stimulated leg before and after six weeks of chronic low frequency stimulation.

Table 4 Change in fatigue index following chronic stimulation for six weeks

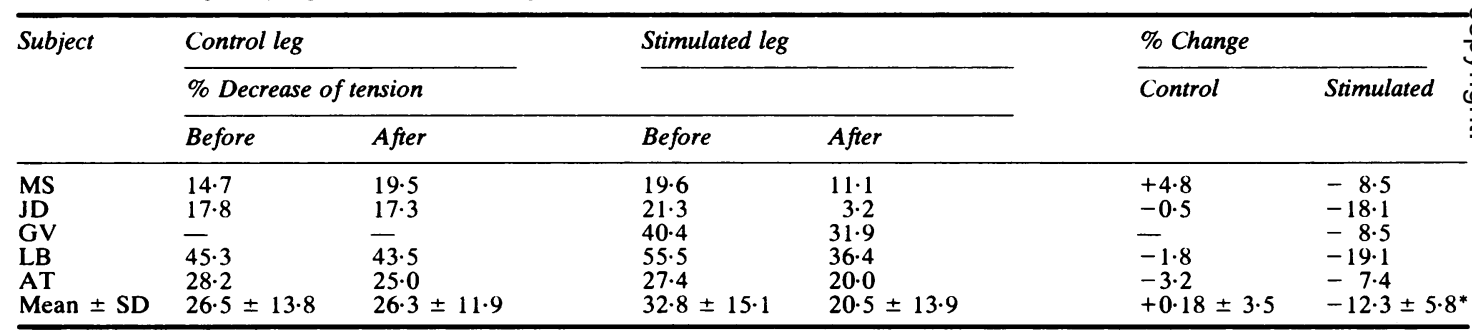

${ }^{*} \mathrm{p}<0.01$

tionship and a high correlation of 0.92 when the maximum voluntary contraction exerted by the anterior tibial muscles of both legs of 18 normal children was plotted against the age.

In response to electrical stimulation at $40 \mathrm{~Hz}$, table 5 shows that the tibialis anterior muscle developed mean tensions of $22 \cdot 1 \pm 9 \cdot 3 \%$ and $23 \cdot 1$ $\pm 10.1 \%$ of the maximum voluntary contraction of the muscles of the right and left legs respectively. Unlike adults, the effect of fatigue testing by stimulating at $40 \mathrm{~Hz}$ for five minutes resulted in little or no decrease of the initial tension exerted by the muscle. The greatest loss of tension, after stimu- lation for three minutes was $19 \%$ and nine children showed a small increase of tension (range 5-40\%). There was however, a highly significant increase in the proportion of tension developed on stimulation at $10 \mathrm{~Hz}$ following the fatigue test of mean values $7.9 \% \pm 8.9 p<0.01$ and $9.7 \% \pm 6.3 p<0.001$ for the muscles of the right and left legs respectively. Similar but more variable mean increases of $4.25 \%$ \pm 13.4 and $7.7 \% \pm 10.8$ were recorded on restimulation at $20 \mathrm{~Hz}$.

Effect of chronic electrical stimulation

There was no significant change in the maximum 


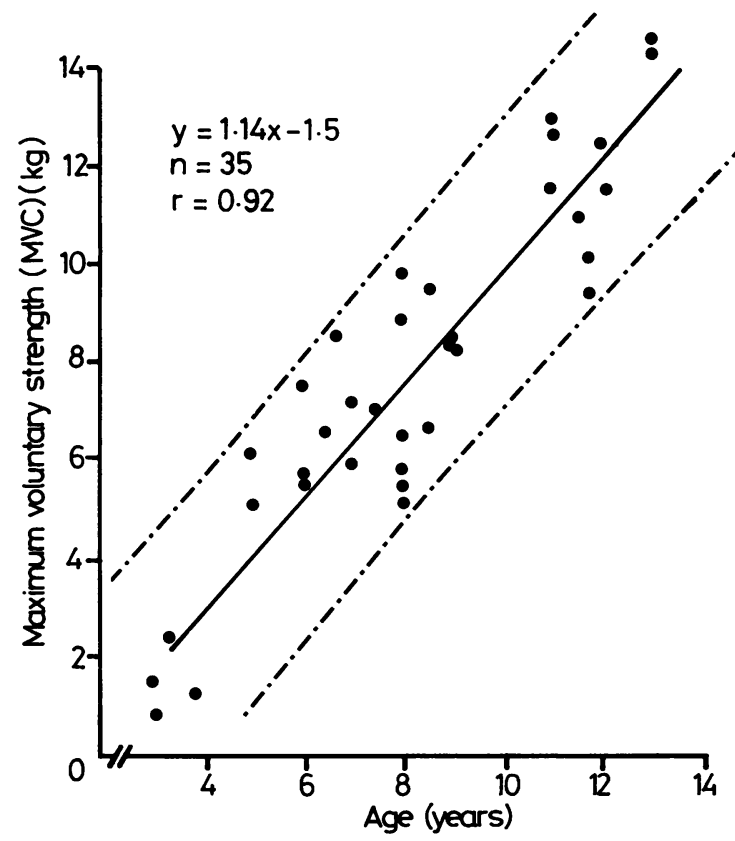

Fig 4 Relationship of the maximum voluntary strength (MVC) of normal children with age. voluntary contraction of the 11-year-old girl following six weeks of low frequency stimulation for one hour, three times daily, neither was there a decrease of initial tension in either leg, prior to commencing six weeks of prolonged low frequency stimulation, nor following the completion of the period of stimulation. Table 6 gives a summary of the results.

\section{Discussion}

The results of this study show that in adults, the tibialis anterior muscle fatigues and its tension decreases after repeated tetanic stimulation. These results are in agreement with those of other researchers $^{8}$ "1" who, using methods of fatigue testing also based on that established by Burke in 1973, ${ }^{7}$ found that adult human muscles show an inability to maintain tension on repeated stimulation by brief trains of $40 \mathrm{~Hz}$. It is likely that the loss of force is due to fatigue of its fast contracting glycolytic fatigueable type II motor units and is not caused by failure of neuromuscular transmission or conduction of the peripheral nerve. Recent experiments using same tests have shown that while muscle tension decreased, the size of the recorded action potential remained unaltered (Lenman JAR, personal com-

Table 5 Mean values $\pm S D$ of maximum voluntary contraction, fatigue indices and the ratios $10 / 40 \mathrm{~Hz}$ and $20 / 40 \mathrm{~Hz}$ before and after fatigue testing in 18 normal children

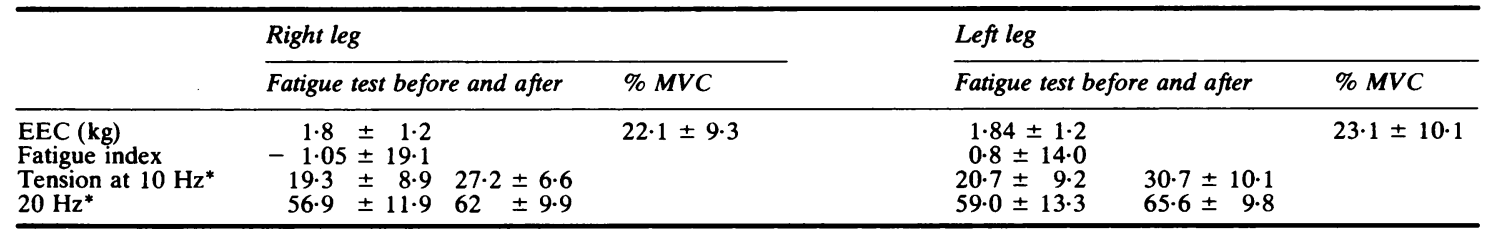

EEC - Electrically elicited contraction at $40 \mathrm{~Hz}$.

$\pm \quad-S D n=17$ for right leg and $n=18$ for left leg.

* - Tension expressed as \% of tension developed at $40 \mathrm{~Hz}$.

Table 6 Tests of muscle function of normal child (AS) before and after 6 weeks of chronic stimulation at $10 \mathrm{~Hz}$ of the left tibialis anterior muscle

\begin{tabular}{|c|c|c|c|c|}
\hline & \multicolumn{2}{|l|}{ Control leg } & \multicolumn{2}{|l|}{ Stimulated leg } \\
\hline & $\begin{array}{l}\text { Before } \\
\text { (13 April 1982) }\end{array}$ & $\begin{array}{l}\text { Afier } \\
\text { (22 May 1982) }\end{array}$ & $\begin{array}{l}\text { Before } \\
\text { (13 April 1982) }\end{array}$ & $\begin{array}{l}\text { After } \\
\text { (22 May 1982) }\end{array}$ \\
\hline $\begin{array}{l}\text { MVC }(\mathrm{kg}) \\
\% \text { MVC stimulated at } 40 \mathrm{~Hz} \\
\text { Fatigue index \% } \\
\text { Force/frequency ratios } \\
\text { Prior to Fatigue testing }\end{array}$ & $\begin{array}{l}9 \cdot 45 \\
32 \\
16\end{array}$ & $\begin{array}{r}9 \cdot 3 \\
20 \cdot 5 \\
+\quad 5\end{array}$ & $\begin{array}{l}10 \cdot 4 \\
21 \\
0\end{array}$ & $\begin{array}{c}9 \cdot 4 \\
21 \\
6\end{array}$ \\
\hline $\begin{array}{l}10 / 40 \% \\
20 / 40 \% \\
\text { After Fatigue testing }\end{array}$ & $\begin{array}{l}19 \\
61\end{array}$ & $\begin{array}{l}20 \\
57\end{array}$ & $\begin{array}{l}18 \\
63\end{array}$ & $\begin{array}{l}21 \\
65\end{array}$ \\
\hline $\begin{array}{l}10 / 40 \% \\
20 / 40 \%\end{array}$ & $\begin{array}{l}34 \\
63\end{array}$ & $\begin{array}{l}23 \\
67\end{array}$ & $\begin{array}{l}46 \\
79\end{array}$ & $\begin{array}{l}35 \\
72\end{array}$ \\
\hline
\end{tabular}


munication). This suggestion is supported by the observed changes in the proportion of tension developed in stimulation by brief trains at $1,10,20$ and $40 \mathrm{~Hz}$ within 2-3 minutes of completion of the fatigue tests. Considerable recovery of tension had already occurred from the low levels recorded at the end of the fatigue test on re-stimulation at $40 \mathrm{~Hz}$. The rapid normalisation of forces elicited at high frequencies corresponds to the reported recovery in relaxation time. ${ }^{5}$ The results of other studies ${ }^{x 11}$ showed comparable responses to high frequency stimulation on retesting 15-20) minutes after completion of fatigue testing. We found that there was a significant change in the proportion of force generated on re-stimulation at $10 \mathrm{~Hz}$.

The mechanism which causes these changes in force output of the muscle fibres is not yet understood although many suggestions have been made. ${ }^{\prime 2}$ Most recently, it has been suggested that modification in the myosin molecule itself occurs, associated with increased phosphorylation of myosin light chains and decrease in energy costs, underlining the close association between the basic structure and biochemistry of muscle and its contractile characteristics. ${ }^{1.3}$

Reviewing the present literature on fatigue in human muscle, it was noted that, with fatigue, the relaxation time increased ${ }^{514}$ and that, during sustained maximum voluntary contraction, there was slowing of the rate of muscle relaxation and a progressive decline in the range and rate of firing suggesting that, as human muscle fatigues, these mechanisms assist in preserving and maintaining tension..$^{15}$

This study demonstrated that, as in animal studies, chronic low frequency stimulation induced an increased resistance to fatigue and this change was clearly seen to take place in the tibialis anterior muscles of normal and adult subjects. An increase in maximum voluntary contraction was not anticipated; only small increases in tetanic tension had been found in animal experiments following chronic low frequency stimulation; ${ }^{16}$ and experience of the effect of exercise in human subjects, ${ }^{17}$ together with these results of chronic stimulation in animals, suggest that the type of adaptation that could be expected would be an increased capacity of the muscle for aerobic metabolism and an increased ability to maintain tension. It is known that changes in the contractile properties occur later than changes in the activity of the oxidative enzymes ${ }^{18}$ and that the activity of these enzymes directly correlates with the fatigue resistance of animal skeletal muscles. ${ }^{14}$ Recent studies of the effect of isometric training for 5 weeks on human elbow flexor muscles showed a significant increase in the fatigue index compared with a control untrained group, but found no differ- ences in the forces of electrically evoked twitch and tetanus. ${ }^{211}$

The finding that there was no decrease of the initial tension in children in response to fatigue testing comparable to that found in adult subjects was something we had not expected. The explanation of their lack of fatigue may be accounted for by the smaller diameters of their muscle fibres and the probability of more efficient diffusion of oxygen making the muscles more resistant to fatigue. Further studies have shown that minimal changes in the half-relaxation time occurred during the five minute test. The apparent increase in tension seen in a few cases during the test could be explained, it has been suggested, because the frequency of stimulation was not sufficient to elicit a maximal tetanic response and that activity produced an increase in the proportion of maximum tetanic tension. However, investigations showed that increasing the frequency of stimulation did not have this effect and the contraction times were not faster, discounting the possibility that higher maximal tensions in these cases were generated by muscle fibres with faster contractile characteristics. Desmedt and his coworkers in 1968 showed marked staircase potentiation of twitch-tension over a 3-minute period in normal children;:2 in our study the highly significant post fatigue potentiation at $10 \mathrm{~Hz}$, and the overall but more variable increases at $20 \mathrm{~Hz}$, indicate that changes do occur in the contractile properties of children during fatigue testing.

The measurements of voluntary strength gave results that were reproducible and similar to comparable studies performed with children.22 2.3 The strength of the ankle dorsiflexors of children showed good correlation with height, weight and age and was included to provide a basis for comparison with other studies in young children. ${ }^{21-2.3}$ No correction was made for the variation of the size of the foot with age as the most common way of expressing strength is still by measurement of anatomically defined forces.

The main point of the present study was to established whether or not it is possible to alter the properties of human muscles in response to superimposed electrical activity and our result has clearly shown that human muscle, like other mammalian muscles, can be altered by chronic low frequency stimulation. The confirmation of this by these results demonstrates the adaptability of human muscles and opens up possibilities for the use of this property in the treatment of some neuromuscular disorders.

We are grateful to the Medical Research Council for supporting this work and to Biochemical Research Limited for supplying the stimulators. 


\section{References}

' Brown M, Cotter M, Hudlická O, Smith ME, Vrbová G. The effect of long-term stimulation of fast muscles on their ability to withstand fatigue. J Physiol (Lond) 1973; 238:47-8P.

2 Bigland-Ritchie B, Jones DA, Woods JJ. Excitation frequency and muscle fatigue: electrical responses during human voluntary and stimulated contraction. Exp Neurol 1979;64:414-27.

${ }^{3}$ Edwards RHT, Hill DK, Jones DA, Merton PA. Fatigue of long duration in human skeletal muscle after exercise. J Physiol (Lond) 1977;272:769-78.

${ }^{4}$ Edwards RHT, Young A, Hosking GP, Jones DA. Human skeletal muscle function: description of tests and normal values. Clin Sci Mol Med 1977;52:28390.

${ }^{s}$ Hultman E, Sjöholm H. Electromyogram, force and relaxation time during and after continuous electrical stimulation of human skeletal muscle in situ. J Physiol (Lond) 1983;339:33-40.

- Freund HJ. Motor unit and muscle activity in voluntary motor control. Physiol Rev 1983; 2:387-431.

${ }^{7}$ Burke RE, Levine DN, Tsairis P, Zajac FE. Physiological types and histochemical profiles in motor units of the cat gastrocnemius. J Physiol (Lond) 1973; 234: 723-48.

${ }^{8}$ Davies CTM, White MJ. Muscle weakness following dynamic exercise in humans. J Appl Physiol 1982;53(1): 236-41.

" Edwards RHT, Newham DJ. Force: frequency relationship determined by percutaneous stimulation of the quadriceps muscle. J Physiol (Lond) 1984;353:128P.

"' Edwards RHT, Jones DA, Newham DJ. Low frequency stimulation and changes in human muscle contractile properties. J Physiol (Lond) 1982;328:29-30.

"Moxham J, Wiles CM, Newham D, Edwards RHT. Sternomastoid muscle function and fatigue in man. Clin Sci 1980;59:463-8.

12 Close RI. Dynamic properties of mammalian skeletal muscles. Physiol Rev 1972;52:129-97.

${ }^{13}$ Kushmerick MJ, Crow M. Chemical energy balance in amphibian and mammalian skeletal muscles. Fed Proc 1982;41,2: 163-8.
${ }^{14}$ Merton PA. Voluntary strength and fatigue. J Physiol (Lond) 1954;123:553-64.

is Bigland-Ritchie B, Johansson R, Lippold OCJ, Smith S, Woods $\mathrm{JJ}$. Changes in motoneurone firing rates during sustained maximal voluntary contraction. J Physiol 1983;340:335-46.

${ }^{16}$ Pette D, Smith ME, Staudte HW, Vrbová G. Effects of long-term electrical stimulation on some contractile and metabolic characteristics of fast rabbit muscles. Pfugers Arch 1973;338:257-72.

${ }^{17}$ Holloszy JO, Booth FW. Biochemical adaptations to endurance exercise in muscle. Am Rev Physiol 1976;38: 273-91.

${ }^{18}$ Pette D, Muller W, Leisner E, Vrbová G. Time dependent effects on contractile properties, fibre population, myosin light chains and enzymes of energy metabolism in intermittently and continuously stimulated fast twitch muscles of the rabbit. Pfugers Arch 1976;364: 103-12.

14 Nemeth PM, Pette D, Vrbová G. Comparison of enzyme activities among single muscle fibres within defined motor units. J Physiol (Lond) 1981;311:489-95.

${ }^{20}$ McDonagh MJN, Hayward CN, Davies CTM. Isometric training in human elbow flexor muscles: the effects on voluntary and electrically evoked forces. J Bone Joint Surg 1983;65B:355-8.

${ }^{21}$ Desmedt JE, Emeryk B, Renoirte P, Hainaut K. Disorder of muscle contraction processes in sex-linked (Duchenne) Muscular Dystrophy with correlative electromyographic study of myopathic involvement in small hand muscles. Am J Med 1968;45:853-72.

22 Asmussen E, Heebøll-Nielsen K, Molbech SV. Descriptions of muscle tests and standard values of muscle strength in children. In: Asmussen E, Fredstedt A. Ryge, eds. "Communications" Hellerup Denmark. The testing and observation institute of the Danish National Association for infantile paralysis 1959:360.

${ }^{23}$ Hosking GP, Bhat US, Dubowitz V, Edwards RHT. Measurements of muscle strength and performance in children with normal and diseased muscle. Arch Dis Child 1976;51:957-63. 